\title{
Virtue ethics: Beyond moral theory
}

\author{
K Koch, ${ }^{1}$ MB ChB; C N Menezes, ${ }^{2}$ MD, MMed (Int Med), Dip HIV Mang (SA), DTM\&H, FCP (SA), Cert ID (SA), PhD \\ ${ }^{1}$ Department of Internal Medicine, Chris Hani Baragwanath Academic Hospital, Soweto, South Africa \\ ${ }^{2}$ General Internal Medicine Unit and Principal Specialist, Division of Infectious Diseases, Department of Internal Medicine, Chris Hani Baragwanath \\ Academic Hospital, Soweto, South Africa
}

Corresponding author: KKoch (karenk@vodamail.co.za)

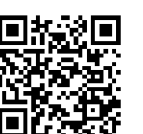

In December 2013, a 52-year-old-man who is a practising Jehovah's Witness was admitted to Chris Hani Baragwanath Hospital (CHBAH), Soweto, Johannesburg. This, the third largest hospital in the world, provides medical services to more than one million local residents. ${ }^{[1]}$ It has the busiest internal medicine unit in South Africa (SA) with 833 beds and a staff comprised of 133 doctors. ${ }^{[2]}$

He presented with an upper gastrointestinal bleed secondary to warfarin use for a left femoro-popliteal deep vein thrombosis diagnosed during a previous admission. At the time of this admission his haemoglobin was $4.5 \mathrm{~g} / \mathrm{dL}$. He was counselled regarding the need for blood transfusion in the face of his ongoing bleed and the lack of other medical alternatives but remained unmoved. Both the patient and his family specifically requested a blood substitute product - a bovine haemoglobin-based oxygen carrier (HBOC) in the face of his critical condition and currently accepted religious practice. The requested product was deregistered in SA in 2008 due to concerns regarding serious cardiovascular side-effects. ${ }^{[3]}$ It can be imported as a section 21 drug for compassionate use but has not been used for several years. ${ }^{[4]}$

The warfarin was stopped and vitamin $\mathrm{K}$ administered to control the bleeding diathesis. All reasonable attempts were made to identify and stop the source of bleeding including gastroscopy and computed tomography (CT) angiography. Despite supportive treatment, his condition deteriorated. It took six days for $\mathrm{HBOC}$ to be approved and imported to South Africa by which time the patient's haemoglobin had dropped to $2.2 \mathrm{~g} / \mathrm{dL}$ and he was experiencing severe shortness of breath, dizziness, weakness and chest pain.

He consented to and received an overall $3.6 \mathrm{~g} / \mathrm{kg}$ of the HBOC over a period of 10 days. He experienced certain transient negative sideeffects. His total haemoglobin increased to $10.5 \mathrm{~g} / \mathrm{dL}$ within three weeks. A repeat Doppler-sonar confirmed the absence of any residual deep vein thrombosis and warfarin was not recommenced.

\section{A simple ethical dilemma}

The dilemma of a Jehovah's Witness declining blood products is not new. Moral theories provide us with a framework to analyse the 'right' decision. We are all familiar with the principles of justice, autonomy, beneficence and non-maleficence outlined by Beauchamp and Childress ${ }^{[5]}$ in The Principles of Biomedical Ethics.

The question of utilising an experimental $\mathrm{HBOC}$ is less obvious. Patients requesting access to experimental treatments raise many ethical concerns. Autonomy, informed consent, non-maleficence ('do no harm') and beneficence are all factors which the treating doctor must address. ${ }^{[5,6]}$

In this case, our patient had clearly declined blood products - a decision well enshrined in medical literature and one which we understood ourselves to be obliged to abide by. In general, we are comfortable with the concept of 'autonomy' as the patient's right to accept or decline treatment. We are not accustomed to extending this concept to embrace the individual's right to access experimental treatments. Without the family specifically requesting such treatment, the experimental nature of the product may have precluded it from entering any patient discussions. ${ }^{[7]}$ The patient was fully aware of the critical nature of his condition, a fact reinforced by his general deterioration over the first week. Dyspnoeic at rest and struggling to sit or eat unassisted, he continued to decline blood product on numerous occasions despite extensive counselling. As a medical team, we involved our haematologists to impress upon the patient both the need for blood product and the fact that use of an $\mathrm{HBOC}$ may not constitute a solution.

His 'informed consent' remained a debatable concession. The patient in extremis cannot always judge whether the burden and inconvenience of participation in novel research is justified. Many people will take any risk (and pay any monetary price, triggering concerns about fraud) if told that the alternative is death. Their incapacity to see and accept their situation is precisely what occasions the need for protecting them.$^{[8]}$ Furthermore, how can the patient understand the risks of using experimental treatment when there are no relevant scientific data to discuss or explain? While trial data may exist, they are usually not specific enough to adequately guide treatment..$^{[5]}$ The principle of benevolence and non-maleficence are crucial concepts when considering experimental medicine. Each cannot be explored in isolation. Benevolence is the principle suggesting that physicians have an obligation to do everything in their power to help their patients by preventing death or improving quality of life or both. ${ }^{[9]}$ Non-maleficence suggests physicians should also do all within their power to avoid harming their patient.'Harm'being considered physical, psychological or spiritual in nature. ${ }^{[9]}$

But how is one to decide which principle carries more weight? Does autonomy trump non-maleficence? Does beneficence mean one must order experimental products for every patient? To what extremes is a physician expected to go in order to fulfill his moral obligation?

\section{No such thing as simple}

Many moral problems in medicine involve tensions between conflicting moral obligations. The tension between the beneficence (wanting to help the patient) and non-maleficence (not wanting to give him undue side-effects) are not clear. In reality, clinical ethical problems are usually complicated. The principle approach is useful but not without flaws. Our course of action was justified, but not without flaws. ${ }^{[10,11]}$ 


\section{Virtue ethics}

So how does one make the 'right' decision? How does one know if one's decision was 'right'? And a more philosophical question - how can we become physicians who make the 'right' decisions?

Physicians make ethical decisions every day. A bed may be allocated in ICU according to the principle of utilitarianism but respect a person's right to decline treatment according to the four principles. ${ }^{[5]}$ We may not even be conscious of the process. Knowing the theory is not the same as implementing it. ${ }^{[10]}$ Virtue ethics suggests that the physician is not simply an inanimate observer in the process of ethical deliberation. They are the living body of ethical practice. The character of the physician will ultimately determine which ethical decisions are made - and if they are made at all. ${ }^{[12]}$

Virtue ethics, dating back to Socrates, Aristotle and Plato, was the primary guiding moral theory before the 17th century. Aristotle believed that certain virtues were necessary to achieve 'the good life. ${ }^{[13]}$

The 'good life' - achieving a state of eudaimonia is 'happiness which is deep, lasting and worth having'. By practising good habits, the physician can reach a state where virtuous behavior is habitual. The reward, according to Aristotle, is that we will exist in a state of eudaimonia. For the rest of us, it means we can sleep at night. ${ }^{[13,14]}$

It makes sense. Most, perhaps all, of us want to be good people - or at least good physicians. We definitely want to make good decisions.

So what makes a good doctor? This is the task that Pellegrino and Thomasma ${ }^{[15]}$ undertake in For The Patient's Good. They argue that the core function of medicine is to improve the well-being of patients. Working toward the patient's good requires a broad range of skills as well as concern for their autonomy and welfare. Good physicians are physicians who do this well. The function of medicine, therefore, implies a number of virtues and skills that will be mastered by a good physician. ${ }^{[14]}$ Beuchamp and Childress ${ }^{[5]}$ suggest these virtues are: trustworthiness, integrity, discernment, compassion and conscientiousness.

Thankfully virtue ethics suggests that we all have the capacity to become 'virtuous'. These are skills which can be acquired and strengthened. Through repetition the virtues become integral to the character of the physician. ${ }^{[12,14]}$

Virtue ethics in practice Understanding moral theory, the management of this patient had two equally compelling options. The dilemma: To give or not to give HBOC? We applied the 'virtues' in analysing the situation.

Compassion: According to Beuchamp ${ }^{[5]}$ this is, '... an active regard for another's welfare with an imaginative awareness and emotional response of deep sympathy, tenderness and discomfort at another's misfortune of suffering'.The faith and temperament of this patient did elicit an emotional response. It created the desire to find a solution.

Trustworthiness: 'Able to be relied on to do or provide what is needed or right.'[16] The patient had exposed his core spiritual beliefs to his doctors. He believed that we would do everything possible to improve his wellbeing while respecting his treatment refusal.

Discernment: The ability to bring 'sensitive insight, understanding and wise judgment', to a situation. ${ }^{[16]}$ In this case the understanding that the patient may well die despite every effort, including use of HBOC. Furthermore the insight that the patient was of sound mind and not swayed by external influences in making his treatment decisions.
Integrity: 'The quality of being honest and fair'.16] The discussion regarding use of $\mathrm{HBOC}$ was forthright. There was no false hope given regarding the product.

Conscientiousness: 'Governed by or conforming to the dictates of conscience.! ${ }^{[16]}$

Conscientiousness led to concern about both giving the $\mathrm{HBOC}$ and not giving the $\mathrm{HBOC}$.

Once the possibility of acquiring HBOC became feasible, compassion was the single strongest motivator swaying the decision.

\section{Balancing virtue ethics}

Virtue theory explains how we can become more moral and perhaps why we would choose to do so. Virtue ethics does not replace bioethics. Rather the virtuous physician would be proficient in moral theory. ${ }^{[10,12]}$

Where more than one course of action is ethically justifiable, moral theory is unable to bridge the gap.

Virtue ethics suggests that the best decision to be made in this scenario is the one made by the virtuous physician. If one is not yet the virtuous physician - applying the virtues can provide clarity. ${ }^{[12]}$

We are fortunate to have among us virtuous physicians. The rest of us continue to strive to achieve this disposition. Without virtue, ethics is simply an obligation. As a profession we owe more to our patients than doing the bare minimum. We also need to do what is right.

\section{References}

1. Republic of South Africa. South African Census 2001. Pali Lehohla; Stats SA. South Africa: Stats SA. 2003. http://www.statssa.gov.za/census01/html/default. asp (accessed 10 January 2013).

2. Chris Hani Baragwanath Hospital. Home Page. Johannesburg: Chris Hani Baragwanath Hospital, 2013. http://www.chrishanibaragwanathhospital.co.za/ departments/internal_medicine (accessed 17 January 2013).

3. Chen J, Scerbo M, Kramer G. A review of blood substitutes: Examining the history, clinical trial results and ethics of hemoglobin-based oxygen carrier. Clinics 2009;64(8):803-813. [http://dx.doi.org/10.1590/S1807-59322009000800016]

4. Hemopure. South Africa OPK Biotech. South Africa: Hemopure, 2013. http:// www.hemopure.co.za (accessed 17 January 2013).

5. Beauchamp T, Childress JF. The principles of biomedical ethics. 6th ed. New York: Oxford University Press, 2008: 336-343.

6. Loutfy M. Changing the Rules in Times of Crisis: Do Desperate Times Allow Desperate Measures? Virtual Mentor. 2006;8(4):214-218. [http://dx.doi. org/10.1001/virtualmentor.2006.8.4.ccas4-0604]

7. United Nations Educational, Scientific and Cultural Organization (UNESCO). Universal Declaration on Bioethics and Human Rights; Adopted by acclamation on 19 October 2005 by the 33rd session of the General Conference of UNESCO. Paris: UNESCO, 2005. unesdoc.unesco.org/images/0014/001461/146180E.pdf (accessed 17 January 2013).

8. Schuklenk U, Lowry C. Terminal illness and access to Phase 1 experimenta agents, surgeries and devices: Reviewing the ethical arguments. Br Med Bull 2009;89(1):7-22. [http://dx.doi.org/10.1093/bmb/ldn048]

9. Steven Pantilat. Ethics Fast Facts. San Francisco: UCSF School of Medicine, 2008 http://missinglink.ucsf.edu/Im/ethics/Content\%20Pages/fast_fact_informed_ consent.htm (accessed 10 January 2013).

10. Clarke DL. Moral principlism alone is insufficient, and traditional moral theories remain important for practical ethics. S Afr J BL 2009;2(2):54

11. Campbell AV. The virtues (and vices) of the four principles. J Med Ethics 2003;29(5):292-296. [http://dx.doi.org/10.1136/jme.29.5.292]

12. Gardiner P. A virtue ethics approach to moral dilemmas in medicine. J Med Ethics 2003;29(5):297-302. [http://dx.doi.org/10.1136/jme.29.5.297]

13. Aristotle. Nicomachean Ethics. New York: Dover Thrift Editions, 1998.

14. Sherman N. The fabric of character. Oxford: Oxford University Press, 1989:7.

15. Pellegrino ED, Thomasma DC. The Virtues in Medical Practice. New York: Oxford University Press, 1994.

16. Merriam-Webster Inc. Merriam-Webster Dictionary. Massachusetts: MerriamWebster Inc, 2015. http://www.merriam-webster.com (accessed 17 January 2013)

S Afr J BL 2015;8(2):48-49. DOI:10.7196/SAJBL.434 